\title{
TITANIC... ESO \\ Les cultures a l'escola després de deu anys de la Reforma
}

\author{
Enrique Fuentes. Àrea de Teoria i Història de l'Educació \\ Isabel Viscarro. Àrea de Didàctica de l'Expressió Corporal
}

Els no tan nens, però encara joves i sense criteri propi, que estudien ESO, viuen sota la tutela sentimental de la seva família i dels seus amics, la pressió intel.lectual dels professors, l'acció d'adoctrinament d'esglésies i governs, l'ansietat biològica pròpia de l'edat i la seducció contínua de la publicitat, la moda i els missatges heterodoxos dels mitjans de comunicació transnacionals que fan de cants de sirenes per als nois i noies de tot el món.

\section{Problemes estructurals}

La generació que els precedeix, en la qual incloem els pares i els seus responsables polítics que han pactat aquest sistema educatiu, pretén deixar un llegat de llibertat i democràcia, però en el fons han estructurat una forma hermètica d'estatu quo.

Tot i que la llei d'Educació de 1990 posa en mans dels Consells Escolars els pactes per a l'educació que desitgen les famílies i la instrucció que promou l'Estat de les Autonomies, mitjançant cursos, nivells i orientacions programàtiques, el cert és que en els centres d'educació secundària els bons propòsits dels legisladors no acompleixen amb el preàmbul de la Llei abans esmentada, que consagra el dret a una educació igualitària encara que diferenciada. Perquè s'han filtrat moltes diferències mitjançant els concordats eclesiàstics que diferencien entre centres concertats, privats i públics, dotant a altres amb objectius difusos $i$ amb recursos oportunistes, obrint-ne d'altres en simples barracons en barris i pobles marginalitzats.

Aquesta mateixa acció educadora i unificadora per la igualtat d'oportunitats, o el que en altres paraules $\mathrm{F}$. M. Enguita (1997) descriu: "La comprehensividad, la coeducación y la integración son las formas que el sistema educativo ha adoptado para que los hijos de los obreros, las mujeres y las minorías étnicas tengan cabida” pateix una distorsió al ser aplicada de diferent manera per les polítiques dels partits nacionalistes que governen, administren i culturalitzen, en les diferents comunitats autònomes de llengua pròpia, afegint al fe- nomen general de desadaptació el problema de la immersió lingüística, i el de l'adaptació dels programes d'humanitats a la visió de la pròpia realitat sociocultural. Juntament amb d'altres fenòmens que apuntarem, han induït els diferents grups de docents a una lluita ideològica desigual, deslegitimadora en alguns casos, i a la desmotivació, desil.lusió i a una certa desídia de la manera de ser postmoderna del tot és vàlid.

Un altre factor important, propi de la ideologia neoliberal que domina en el món empresarial i que es transvasa artificialment a les institucions públiques, és la tendència a valorar més, tant a nivell professional i de sou com de prestigi social, els gestors i administradors que els bons docents i intel.lectuals. Davant els tecnòcrates que controlen les noves institucions, té la mateixa vàlua un professor experimentat que un oportunista al qual li queda molt per aprendre en tots els sentits. L'important és que cadascú es quedi al lloc assignat i no generi problemes organitzatius, i val més no parlar del sector endogàmic que fa, de la professió docent, un simple treball remunerat i sense compromisos ètics, dins de les pròpies economies familiars.

\section{Percepció de cultures diferents}

Deixem de banda aquests greus problemes estructurals $\mathrm{i}$ analitzem com perceben els joves d'entre 13 i 16 anys les pròpies cultures, la familiar, la social i l'escolar. La cultura familiar té molt a veure amb l'ideari que es va marcar la parella a l'iniciar la seva vida en comú. Com ha dit Gary Becker (1987) al seu llibre: «Tratado de la familia", a l'època actual la qualitat en l'educació, la inversió en formació, sobre la tradicional quantitat de fills per a la producció han tingut com a conseqüència una dràstica disminució de la natalitat. A Catalunya la mitjana no arriba a dos fills per parella, exactament és d'1,2; més baixa que a la resta de la Comunitat Europea. El consum ostentós fa que la primera obligació dels pares sigui "que no els falti res" al seu o seus fills... i aquests creixen tenint-ho tot sense cap esforç, excepte el de demostrar estimació i fer les quatre tasques que 


\section{T e m a d e s c o I a}

els encomanen. No es tracta de generalitzar, però realment s'està educant els fills quat se'ls dóna tot el que demanen? o és una manera de compensar la dedicació que necessiten i que de vegades, per motius diversos, no se'ls pot donar? Possiblement el fet de poder comprar tot el que els joves volen no els permet valorar la importància de les coses, perquè no valoren l'esforç propi.

Treball, llar i oci estan intrínsecament units a la societat postindustrial; els pares, seguidors de la modernitat, comparteixen les tasques professionals amb d'altres activitats socials. Així doncs, és lògic que compartimentalitzin el seu temps, funcionalitzin els seus múltiples deures amb l'empresa, els amics, la família, i amb ells mateixos. És el culte al jo. Com es pot ser individu i pare a la vegada?

La relació amb els fills queda, sovint, ritualitzada: anar junts a certs llocs, alguns dies, a hores determinades, tal com fan alguns divorciats els dies que tenen els fills. Altres vegades volen ser els seus únics amics, la relació és tan tancada que no arriben a comprendre que els seus fills adolescents no volen estar a casa amb ells, on ho tenen tot, i per això el que desitgen és tot el contrari: vestir-se amb altra roba, menjar malament, dir paraules gruixudes i malsonants, tornar tard a casa, anar a l'estranger, i també sortir amb aquell que té tan mala pinta. L'important per a ells és sortir-se de la norma per construir la seva cultura, aquella que en diuen juvenil. I necessiten fer-ho així per autoafirmarse.

En els estadis contemporanis el pas de l'educació estatal a l'educació nacional de Catalunya ha d'integrar de manera anòmala les cultures familiars dels grups ètnics diferencials, uns autèntics espanyols, ciutadans de plens drets sobirans com els gitanos, altres afegits per la Unió Europea i uns altres procedents de la resta del món on les comunitats àrabs, xinesa, etc. aporten elements culturals de dimensió universal. L'administració té por que en certs centres escolars s'imposi de manera predominant un model cultural que no és el del grup majoritari, i que té una llengua com és l'àrab i una religió com la islàmica, que els identifica i preassimila a milions

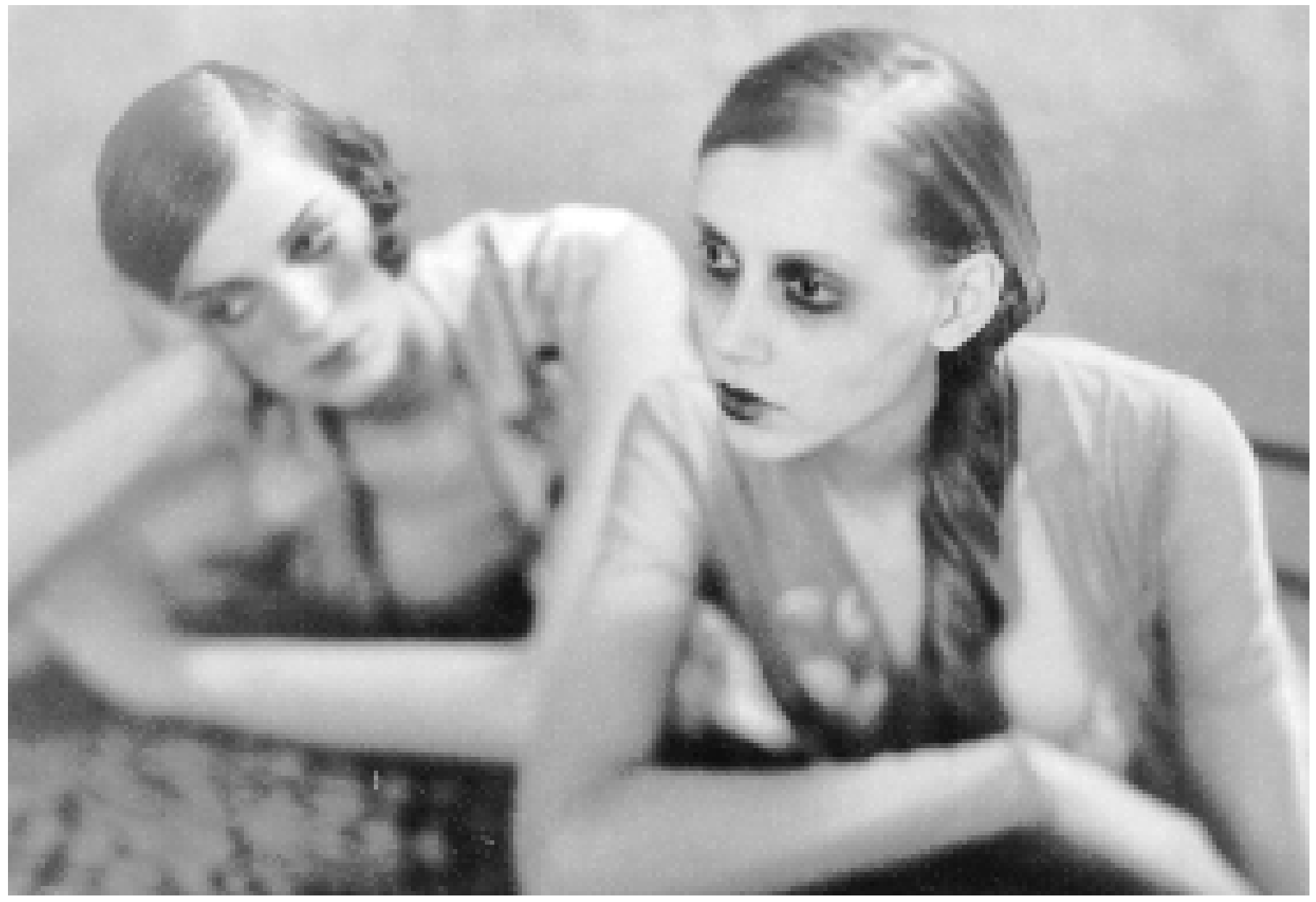




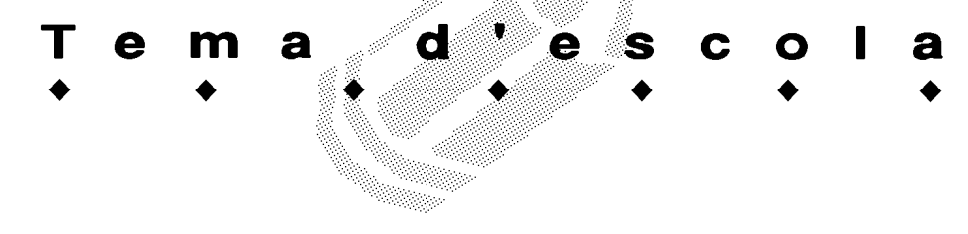

d'éssers humans. Una escletxa que enriqueix o separa, segons el tarannà dels professors, joves amb sentits de la vida, la familia i les necessitats socials nítidament diferents.

\section{Els joves de la secundària}

Els escolars de secundària, siguin noies o nois, estan passant per un procés d'endoculturació dirigit intencionalment en termes de mercat i consum. Això fa que la percepció d'ells mateixos no es refereixi als rols jugats pel pare o la mare, o per imperatius morals de la religió, sinó a un complex sistema de models de conducta que fan tremendament ambigua l'elecció d'una identitat cultural específica.

Les noies han estat influenciades pel món de les top models, amb una preocupació sovint exagerada per les mesures corporals i pel pes, fins a l'extrem d'induir-les a dietes alimentàries extremes, que les han portat a la vora de l'anorèxia i de la talla 36 . Els nois, potser en una lluita agònica per rescatar els últims privilegis de la cultura masclista, també han adoptat models en la seva manera de rapar-se el cabell a l'estil militar, o d'ostentació falonarcisista amb gecs i pantalons cenyits, destacant pel damunt de tot el ressorgiment de formes de violència vandàlica, a vegades fruit de la seva neurosi agressiva, socialment no justificada, encara que en el cas del terrorisme anomenat de baixa intensitat estigui políticament manipulada.

L'espiral del consum se sustenta en el poder adquisitiu de les classes mitjanes, que a Europa i als Estats
Units d'Amèrica és molt superior a la de la resta del món. Això comporta l'adquisició d'objectes que van des de la bicicleta al cotxe, de l'enciclopèdia a terminis a l'ordinador multimèdia, imprescindibles per fer els deures. Tot això demana una reorganització del model de vivenda on no falti el cablejat per a Interneti el canal Satè/.lit.

Davant tanta saturació, no és d'estranyar que les noies i nois busquin refugi en el nihilisme, en l'autodestrucció, en el dolor infundat del tatuatge i els claus punxats (piercing) o a buscar la seva identitat en la personalitat social combativa per tal de conquerir altres territoris encara que siguin simbòlics, ja sigui en la seva pròpia habitació, al water de l'institut o al lloc on ningú els reconeixerà, lluny del barri, en after hours, o per on va la ruta del bacalao.

Com sempre ha passat, els joves es redimeixen a ells mateixos, en la majoria dels casos sense consells ni teràpies, amb la inserció laboral i en la topada amb l'amor que els portarà a crear la seva pròpia llar i un nou cicle de vida i de cultura, del qual seran responsables.

Una nova cultura no apareix del no-res, per això l' escola secundària és tan important en el procés de transmissió d'experiències culturals, més enllà de les pròpies obres artístiques o industrials, i mitjançant el coneixement del pensament universal, on hi és present Orestes, o Virgili, especialment Romeo i Julieta, la millor música, els còmics, aquest cinema únic que ens ha deixat el segle $X X$, i també cal esmentar el chati el Net-Meeting que ens projecten al món global i virtual del proper segle.

Per assolir aquests objectius generals i l'ambient

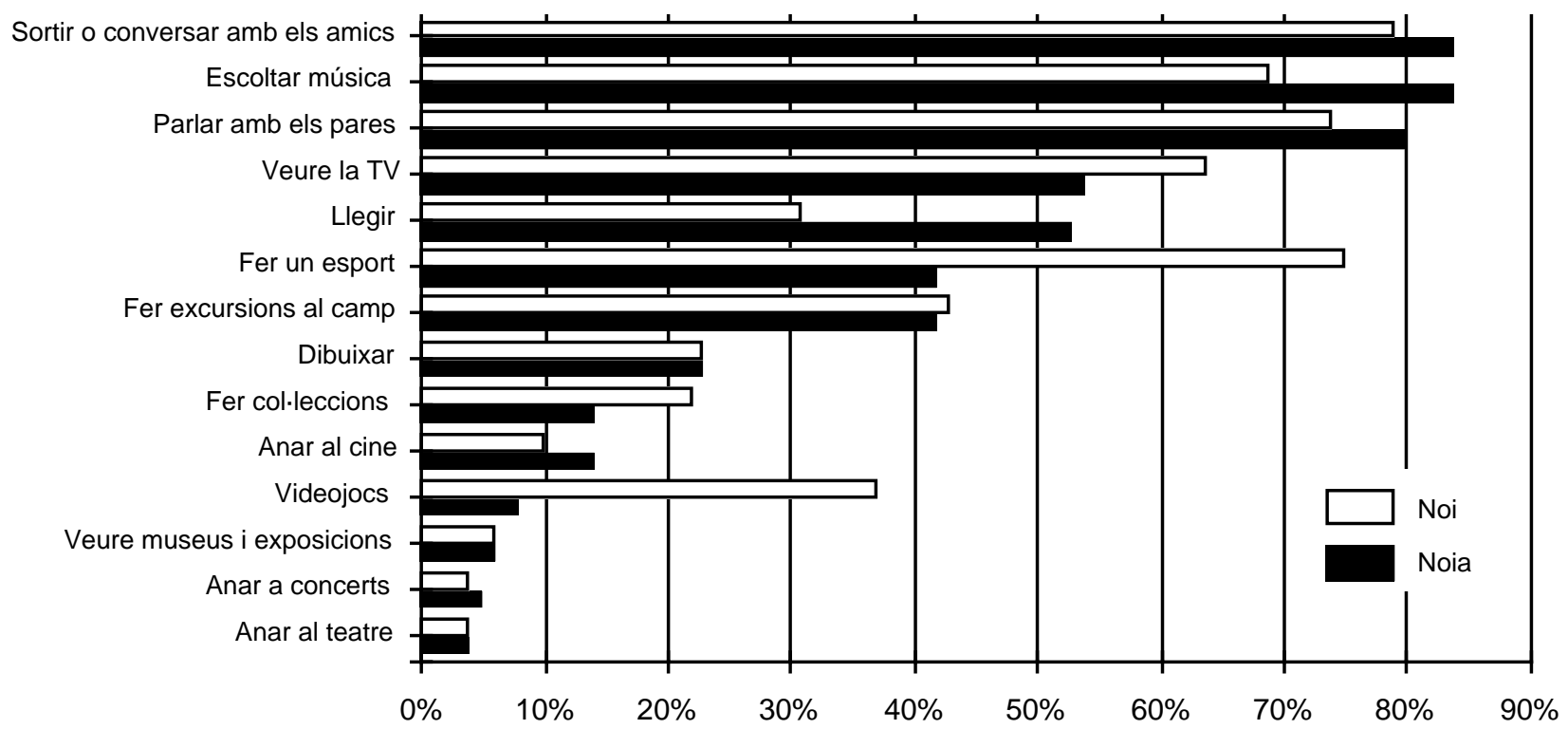

Temps dedicat a activitats fora del centre escolar, segons el sexe. Els percentatges corresponen a noies i nois que han contestat amb bastant o molt a les qüestions plantejades. (INCE, 1997). 


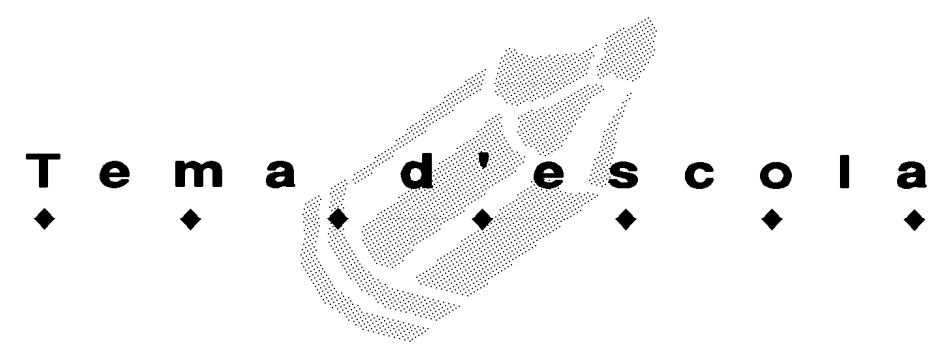

propici per als aprenentatges funcionals, l'ESO no ha estat una de les millors idees.

Segons un estudi del Ministerio de Educación i Cultura, en què s'analitzen les cultures familiar i escolar en relació al Sistema Educatiu (1997), la cultura juvenil té una gran relació amb els pares joves i comprensius. Però uns i altres, potser per falta de temps o per qüestions econòmiques, es van distanciant de manifestacions culturals més emblemàtiques com el teatre o la música clàssica. Als centres s'hauria de canalitzar de manera formativa el potencial educatiu de la música. Lipovetsky (1986) a la seva obra La era del vacío compara els joves aïllats en el seu walkmanamb la música a tota potència, ja sigui a la seva habitació, al cotxe, al carrer... amb els zombies.

També els centres haurien de dedicar més personal $\mathrm{i}$ recursos a l'educació física i esportiva, ja que és altament beneficiosa per als joves d'aquestes edats. Dels molts beneficis que aporta l'activitat física i esportiva a la persona, en destacarem un parell. Per una banda, els permet descarregar l'agressivitat que porten i canalitzar aquesta energia i vitalitat de forma positiva, afavorint el seu creixement personal i social. I per l'altra, els ajuda a crear i/ o consolidar uns hàbits posturals higiènics, de cura i manteniment del propi cos, que a més a més d'afavorir la seva autoimatge i autoafirmació, els allunyarà de l'interès absurd

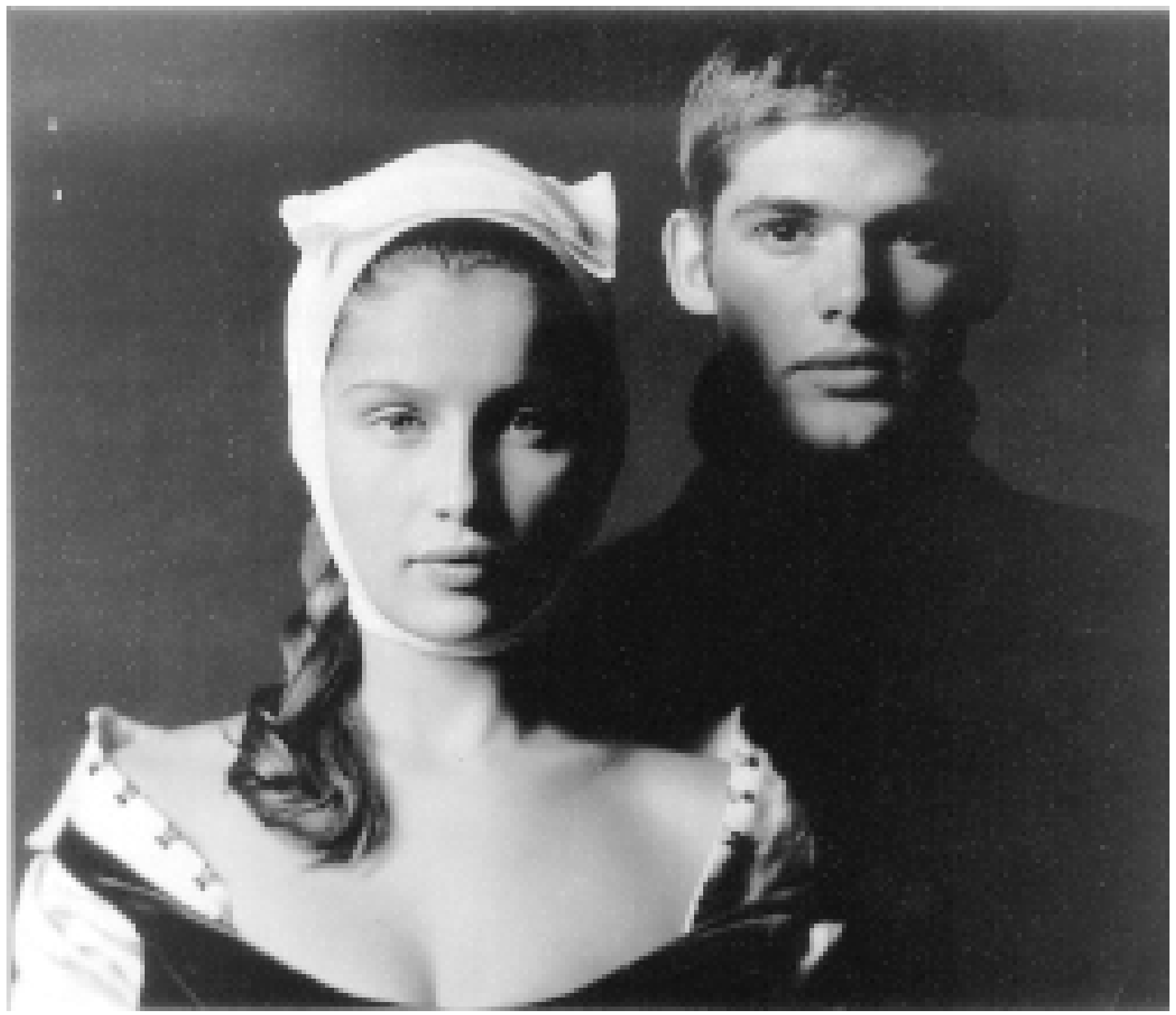




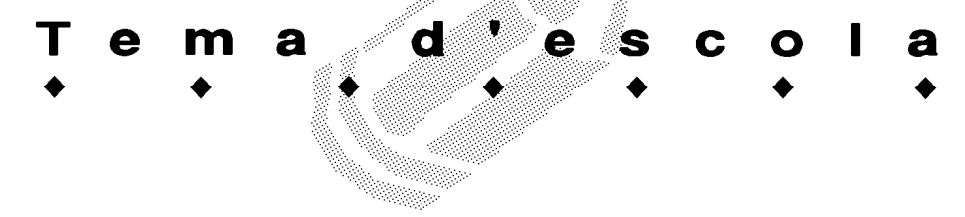

per les dietes que els poden portar a formes d'aprimament malaltisses (anorèxia, bulímia...) o al narcisista body builder que els distanciarà del sentit social del diàleg corporal.

Per això pensem que els nous centres de secundària no són calaixos, sinó centres espirituals on s'anima a la representació d'obres de teatre, a la interpretació musical i coral, a l'esport alliberador, a delectar-se amb la lectura, a gaudir de les matemàtiques i la física en el centre experimental. Per això el professorat s'ha de rejovenir, s'ha de posar a la seva pell, s'ha de fer la cirurgia estètica de la pedagogia per als joves.

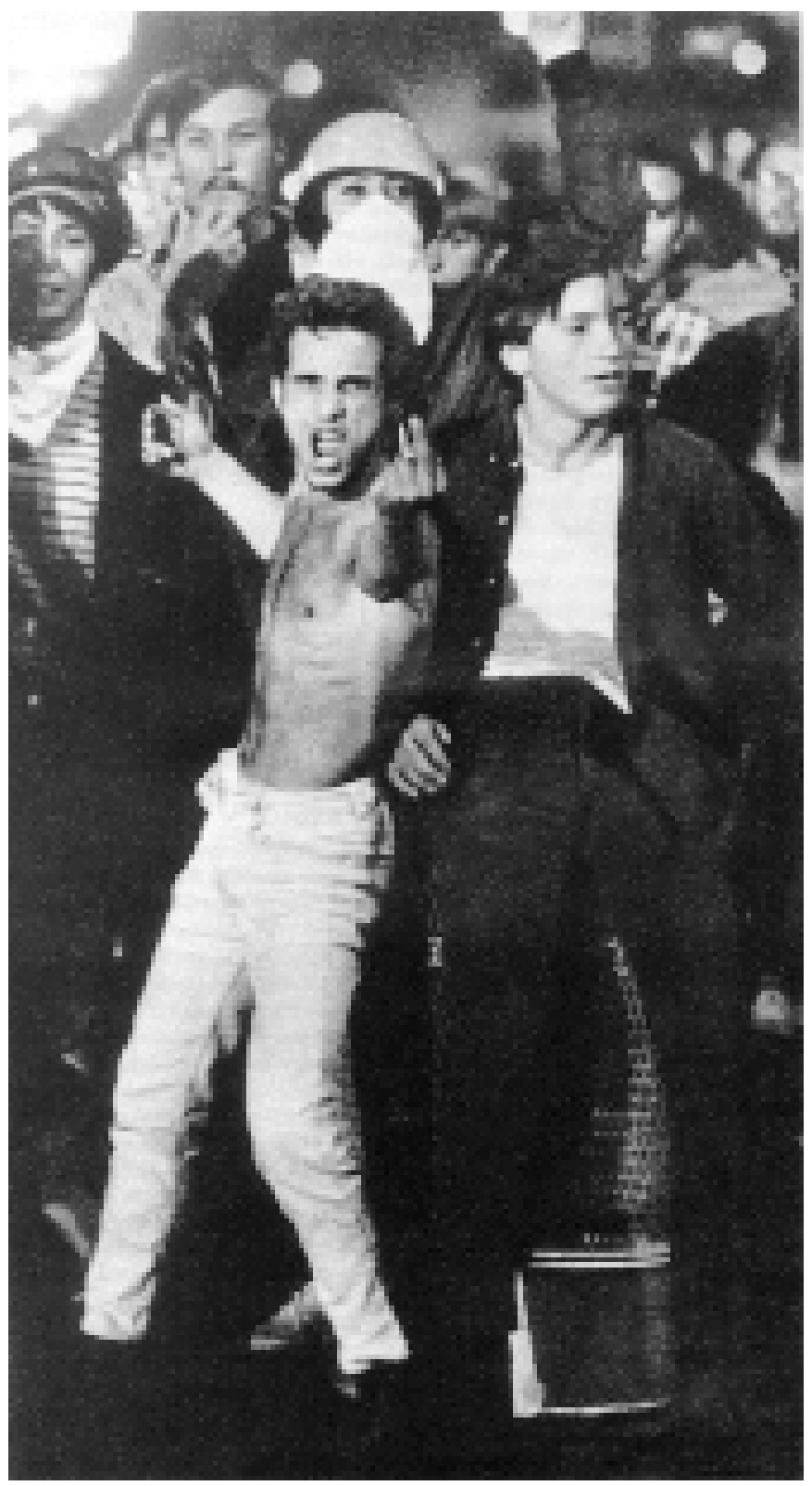

\section{Què és ESO?}

Per una part no aporta un coneixement sòlid de les cultures clàssica i moderna, tampoc fa una distinció útil entre aprenentatge intel-lectual i formació professional. Separa les clases socials d'una manera cada cop més dràstica entre centres concertats i centres públics, mal dotats en tots sentits. No ha sabut organitzar les ensenyances d'acord amb la nova sociologia del professorat: els catedràtics amb antiguitat estan desmotivats per la baixada de nivell, conseqüència de la incorporació d'alumnes que acumulen fracàs escolar i dislèxies; altres professors estan marginats davant els gestors públics, i d'altres no s'han adaptat als requeriments de la nova situació. Els primers cursos encara són infantils, els últims procaçment madurs. La feminització de l'ensenyament no està suficientment estudiada per reconduir els centres- a un equilibri entre gèneres, tan ric dins de la cultura familiar i tan mancat de sentit en una etapa on les noies i els nois busquen un model comportamental.

L'administració es preocupa més de l'estabulament que dels paràmetres formatius; no admet el seu fracàs en el disseny curricular, ni en la falta de coordinació entre els plans d'estudis que siguin competents, tant interestatalment com a nivell europeu. S'han degradat, desarticulat i improvisat les ensenyances bàsiques, aquesta ESO semblava el Titànic que, a tota màquina, havia de creuar l'Atlàntic del pròxim segle, i s'està enfonsant quan encara no ha complert els deu anys. S'està sacrificant una generació de joves per la baixa qualitat de l'ensenyança, amanida amb els pitjors ingredients de la cultura (escombraries) en què es mou l'ambient juvenil. Si "Torrente, el brazo tonto de la ley" ( The Top Ten Box-Office Hits) és l'exponent de pel-lícula majoritàriament vista pels escolars, i el tecno dur és l'únic que els fa moure, pensem que haurem de desmuntar el vaixell abans de enfonsarnos amb ell. Estem parlant del conjunt d'una nació, no de l'interès mesquí d'una classe social privilegiada. Quan una educació emmalalteix, tots morim una mica. Si alguna cosa hem de deixar d'herència a les dones i homes del segle que ve, que sigui l'honor i el prestigi de les nostres Institucions Educatives.

\section{Referències bibliogràfiques}

ENGUITA, M. F. Sociología de la educación. Editorial Ariel. Barcelona. 1997. Pàg. 440.

BECKER, G. Tratado de la familia. Alianza editorial. Madrid. 1987.

Las culturas familiar y escolar en relación al Sistema Educativo. Editat pel Ministerio de Educación y Ciencia. Madrid. 1997.

LIPOVETSKY, G. La era del vacío. Editorial Anagrama. Barcelona. 1986. 